\title{
MicroRNA-New Category of Diagnostic Biomarkers
}

\author{
David Stejskal ${ }^{1,2 *}$, Martina Hložánková ${ }^{3}$, Radka Šigutová ${ }^{1,2}$ and Zdeněk Švagera ${ }^{1,2}$ \\ ${ }^{1}$ Institute of laboratory diagnostics, University hospital Ostrava, Czech Republic \\ ${ }^{2}$ Faculty of medicine Ostrava University, Czech Republic \\ ${ }^{3}$ Biovendor R\&D, Brno-Karásek, Czech Republic
}

Submission: June 06, 2018; Published: August 22, 2018

"Corresponding author: David Stejskal, Zdeněk Švagera Institute of laboratory diagnostics, University hospital Ostrava,Czech RepublicZdeněk

Švagera, Czech Republic, Email: zdenek.svagera@fno.cz

Keywords: MiRNA; MicroRNA; ELISA;PCR; NGS;Immunomethod;Microarrays

\section{Introduction}

MicroRNAs (miRNA) are small (21-24 nucleotides) noncoding RNAs which are involved in negative posttranscriptional regulation of gene expression. One miRNA molecule can have up to hundreds of target mRNAs and one mRNA can be regulated by multiple miRNAs, creating a complex regulatory network in the body/organism [1].Changes in intracellular miRNA levels affect gene expression, alter cell signaling, and significantly affect cellular metabolism. They regulate physiological processes including cell differentiation, regeneration and apoptosis, as well as pathological processes such as neoplastic transformation of cells. Therefore, it is not surprising that aberrant miRNA expression is involved in the pathogenesis of many diseases including cardiovascular diseases, neurodegenerative diseases and cancer. To this day, more than 2,500 different microRNAs have been described in various documents [2-7]

In addition to the intracellular occurrence, microRNAs were also detected in the extracellular area - in the blood and its derivatives (plasma, serum), but also in the urine, saliva and other body fluids. 5,6 It has been proven that levels of circulating microRNAs are not random and reflect the events occurring within the organism/body. The gathered data, together with the proven high miRNA stability, place the circulating miRNA into the role of potentially useful, clinically relevant biomarkers. Finding specific miRNAs or groups (profiles) of several miRNAs at once, in order to serve as diagnostic or prognostic sets, is now one of the main targets of research in this area [2-8].

\section{Methods}

Detection and quantification of small non-coding RNAs is a challenging and interesting topic of contemporary science. Not only a small length of these molecules (about 25 nucleotides) and their low concentration in body fluids, but also the existence of sequence differences in unit bases in some types of short RNA
(isomiRs), are key points for using these molecules as markers in routine diagnostics. The most common techniques for detecting small RNAs can be divided into many groups, and their combinations: Polymerase Chain Reaction (PCR), Microarrays, New Generation Sequencing (NGS), etc. [9-11]. Recently, a new immunomethod for detection miRNA was described.

\section{Results}

\section{Detection technology based on PCR}

Since the discovery of reverse transcription PCR (RT PCR), PCR-based systems are the most widely used methods for detecting RNA sequences. In this technology, the RNA molecule is first enzymatically transcribed (via the reverse transcriptase enzyme and the RT primer) into the cDNA sequence, which is then amplified by DNA polymerase using two specific primers. The PCR reaction can be visualized in real time (qRT PCR) using a sequence non-specific (Sybergreen) or sequence-specific (TaqMan system) fluorescent labels/markers. Unfortunately, in the context of short RNA detection, this standard qRT PCR system is not well suited because the RT primers do not have enough space to bind the target RNA due to their short length. Therefore, new approaches to the detection of short RNA molecules have to be applied, such as using a special RT primer, amplification of circular molecules (RCA), poly-tailing reaction or ligation reaction. So far, several methods of quantification of miRNA based on qRT PCR have been developed, and many of them are also commercially available[12, 13].

\section{Detection technology based on microarrays}

Microarrays (DNA / RNA chips) use a hybridization process that naturally parallels complementary DNA and RNA sequences. In case of a microarray, a synthetic DNA probe is bound to the defined position of a solid surface, designed to complement the sequence observed. Many DNA probes can be bound on 
a small surface, and different colors of fluorescent labels can be used to visualize hybrids. This reveals the main strength of micro multiplexing. The latest commercial detectors of miRNA (GeneChip miRNA 4.0 Arrays - ThermoFisher Scientific, miRCURY LNA microRNA arrays - EXICON)[14] are capable of measuring hundreds of miRNAs in one sample, plus miRNA targets can be selected according to customer needs. In principle, microarrays should provide highly quantitative information on nucleic acid concentration. In practice, however, there are significant quantitative bias between different genes and transcripts. As a result, microarrays are typically considered as a tool to relative quantification of different miRNA targets rather than to determine absolute concentration. Additionally, sensitivity of detection of microarrays is limited by sensitivity of the fluorescence detector, which means that very expensive devices are needed. For these reasons, microstructures are mainly used for differential analysis of profiles of miRNA expression profiles, but not for normal/routine measurements of concentration [1516]own experiences.

\section{NGS}

NGS is a group of approaches for massively multiplexed sequence analysis of DNA and RNA. Unlike traditional Sanger sequencing, which requires an input in form of a homogenous DNA template, NGS allows the analysis of heterogeneous samples while providing sequential information for more than 10 million randomly selected molecules of nucleic acid within the sample. Because of the large quantity of reads, NGS is uniquely suited for the analysis and diagnosis of nucleic acids requiring multiplex analysis of many genes and their variants. There are several NGS accesses and compatible devices on the market. The most common is Illumina, which is based on the sequential addition of fluorophore marked nucleotides in combination with fluorescence imaging. NGS is the most sensitive method of miRNA identification and quantification. The advantage of this technology is the possibility to discover new short RNAs that have not yet been described. However, the whole NGS process is very time-consuming and requires a high volume of samples. It is also very expensive - it requires chemicals, instruments/ equipment and highly sophisticated evaluation software[17-18].

\section{Immuno-method for the detection and quantification of microRNA}

A substantial number of molecules, including microRNAs are reported as disease markers for various human pathologies. Only a small fraction will be translated to clinical routine use. Major challenge is the reliable measurement of novel markers on platforms that are commonly used in clinical laboratories. Although current molecular methods used to measure miRNA biomarkers, such as qRT-PCR and NGS, are available in selected clinical laboratories, they are rather expensive. Moreover, compatibility with clinical high-throughput workflows is challenging. The adaption of miRNA assays to platforms and technologies that would overcome those issues may foster their use. One of the technologies, which overcome the problems of the current test formats mentioned above, is immunoassay platform, which has a short time-to-result and is faster than NGS. At the same time, the assay is inexpensive. Among the most important points with respect to immunoassay is that the required hardware is installed in many central laboratories of hospitals worldwide.

Immunoassay platforms are already routinely used in clinical laboratories worldwide, and many immunological tests are carried out on these commercial systems. Immunoassays are also adaptable to immunoassay analyzers. The general principle of immunoassay technique is detection or quantification of analyte (microRNA) in the sample comprising an immune reaction between an antibody and an analyte [19].

\section{Discussion}

Immunoassay platforms are already routinely used in clinical laboratories worldwide, and many immunological tests are carried out on these commercial systems. Immunoassays are also adaptable to immunoassay analyzers. The general principle of immunoassay technique is detection or quantification of analyte (microRNA) in the sample comprising an immune reaction between an antibody and an analyte.

In conclusion, we presented new innovative technique for quantification of miRMA based on ELISA. These methods are cheap and can be use in routine laboratories.

\section{Acknowledgements}

This study was supported fromInstitutional support for a long-term conceptual development of research organisationsupported by MZ CR RVO-FNOs/2018.

\section{References}

1. Liang J, Wu X, Sun S, Chen P, Liang X, et al. (2018) Circular RNA expression profile analysis of severe acne by RNA-seq and bioinformatics. J Eur Acad Dermatol Venereol.

2. Gottmann P, Ouni M, Saussenthaler S, Roos J, Stirm L, et al. (2018) A computational biology approach of a genome-wide screen connected miRNAs to obesity and type 2 diabetes. Mol Metab 11: 145-159.

3. Yang TT, Liu CG, Gao SC, Zhang Y, Wang PC, et al. (2018) The Serum Exosome Derived MicroRNA-135a, -193b, and -384 Were Potential Alzheimer's disease Biomarkers. Biomed Environ Sci 31(2): 87-96.

4. McKeever PM, Schneider R, Taghdiri F, Weichert A, Multani N, et al. (2018) MicroRNA Expression Levels Are Altered in the Cerebrospinal Fluid of Patients with Young-Onset Alzheimer's disease. Mol Neurobiol.

5. Kian R, Moradi S, Ghorbian S (2018) Role of components of microRNA machinery in carcinogenesis. Exp Oncol 40(1): 2-9.

6. Zhu H, Leung SW (2018) Identification of Potential MicroRNA Biomarkers by Meta-analysis. Methods Mol Biol 1762: 473-484.

7. Amin M, Islam F, Gopalan V, Lam AK (2018) Detection and Quantification of MicroRNAs in Esophageal Adenocarcinoma. Methods Mol Biol 1756: 257-268.

8. Etheridge A, Wang K, Baxter D, Galas D (2018) Preparation of Small RNA NGS Libraries from Biofluids. Methods Mol Biol 1740: 163-175. 
9. Ren FH, Yang H, He RQ, Lu JN, Lin XG (2018) Analysis of microarrays of miR-34a and its identification of prospective target gene signature in hepatocellular carcinoma. BMC Cancer 18(1): 12.

10. Chen X, Zhang Q Ma W, Lan T, Hong Z, et al. (2018) The Abnormal Expression of MicroRNA-542-3p in Hepatocellular Carcinoma and Its Clinical Significance. Dis Markers 2018: 3973250.

11. Lian J, Lin SH, Ye Y, Chang DW, Huang M, et al. (2018) Serum microRNAs as predictors of risk for non-muscle invasive bladder cancer. Oncotarget 9(19):14895-14908.

12. Huang J, Wu J, Li Y, Li X, Yang T, et al. (2014) Deregulation of serum microRNA expression is associated with cigarette smoking and lung cancer. Biomed Res Int 2014: 364316.

13. Konta T, Ichikawa K, Suzuki K, Kudo K, Satoh H, et al. (2014 ) A microarray analysis of urinary microRNAs in renal diseases. Clin Exp Nephrol 18(5): 711-717.
14. Yin JQ Zhao RC, Morris KV (2008) Profiling microRNA expression with microarrays. Trends Biotechnol 26(2): 70-76.

15. Dard-Dascot C, Naquin D, d'Aubenton-Carafa Y, Alix K, Thermes C, et al. (2018) Systematic comparison of small RNA library preparation protocols for next-generation sequencing. BMC Genomics 19(1): 118.

16. Creighton CJ, Reid JG, Gunaratne PH (2009) Expression profiling of microRNAs by deep sequencing. Brief Bioinform 10(5): 490-497.

17. Kappel A, Keller A (2017) miRNA assays in the clinical laboratory: workflow, detection technologies and automation aspects. Clin Chem Lab Med 55(5): 636-647.

18. Kappel A, Backes C, Huang Y, Zafari S, Leidinger P, et al. (2015) MicroRNA in vitro diagnostics using immunoassay analyzers. Clin Chem 61(4): 600-607.

\author{
Your next submission with Juniper Publishers \\ will reach you the below assets \\ - Quality Editorial service \\ - Swift Peer Review \\ - Reprints availability \\ - E-prints Service \\ - Manuscript Podcast for convenient understanding \\ - Global attainment for your research \\ - Manuscript accessibility in different formats \\ ( Pdf, E-pub, Full Text, Audio) \\ - Unceasing customer service
}

Track the below URL for one-step submission https://juniperpublishers.com/online-submission.php 